SHORT REPORT

\title{
Severe cerebral congophilic angiopathy coincident with increased brain aluminium in a resident of Camelford, Cornwall, UK
}

\author{
C Exley, M M Esiri
}

In July 1988, 20 tonnes of aluminium sulphate was discharged by the South West Water Authority into the drinking water supplied to a large region of North Cornwall. Up to 20000 people were exposed to concentrations of aluminium which were 500-3000 times the acceptable limit under European Union legislation $(0.200 \mathrm{mg} / \mathrm{l})$. Although this incident is currently the topic of a government inquiry, nothing is known about its longer-term repercussions on human health. The first neuropathological examination of a person who was exposed and died of an unspecified neurological condition was carried out. A rare form of sporadic early-onset $\beta$ amyloid angiopathy in cerebral cortical and leptomeningeal vessels, and in leptomeningeal vessels over the cerebellum was identified. In addition, high concentrations of aluminium were found coincident with the severely affected regions of the cortex. Although the presence of aluminium is highly unlikely to be adventitious, determining its role in the observed neuropathology is impossible. A clearer understanding of aluminium's role in this rare form of Alzheimer's related disease should be provided by future research on other people from the exposed population as well as similar neuropathologies in people within or outside this group.

n n 1988 a woman, then aged 44 years, was exposed, over a number of weeks, to high concentrations of aluminium in the water supply as a consequence of 20 tonnes of aluminium sulphate being accidentally discharged into the local mains supply. This incident, which took place in the vicinity of Camelford, Cornwall, UK, is currently the topic of an inquiry by the Department of Health (http://www. advisorybodies.doh.gov.uk/cotnonfood/lowermoor.htm).

Fifteen years later, in May 2003 the woman, by then aged 58 years, was referred for investigation of deterioration of her mental state, which extended back over a period of several months. She had developed difficulty in finding words, problems with simple calculations and a heightened tendency to visual hallucinations. She also complained of headaches. The course was somewhat fluctuating, with no clear progressive course initially. On examination, she was unable to name objects or carry out any but very simple commands. No weakness, sensory change or dysarthria was observed. Her blood pressure and systemic examination were normal. A CT scan showed patchy ischaemic changes in cerebral white matter. By February 2004 she was aphasic, had lost weight and appeared anxious. Tone had now increased in the legs and there was an abnormal startle response and limited up gaze. Gait was, however, intact. She continued to deteriorate and died in April 2004. At the request of the coroner's office, we carried out a neuropathological examination of the brain.

A postmortem examination showed normal systemic findings apart from some pulmonary congestion. The brain weighed $122 \mathrm{lg}$ and appeared normal macroscopically, apart from a slight pigment loss in the substantia nigra and locus coeruleus. On microscopic examination, we found severe, widespread congophilic angiopathy in cerebral cortical and leptomeningeal vessels and in the leptomeningeal vessels over the cerebellum. Cerebral cortical arterioles and capillaries in all main lobes were severely affected. The affected vessels immunostained strongly for $\beta$ amyloid protein (figs 1, 2). Only a few parenchymal argyrophilic plaques, also immunoreactive for $\beta$ amyloid protein, were present in the perivascular regions; almost all of them were diffuse rather than neuritic in character. The few neurofibrillary tangles that were observed were confined to the transentorhinal and periamygdaloid cortex and hippocampus (Braak stage $1 / 2){ }^{1}$ Some loss of neurones in layers 2 and 3 of the cortex was evident, with associated laminar spongy change and gliosis. Immunostaining for protease-resistant prion protein was negative. Some of the congophilic cortical arterioles showed small deposits of haemosiderin around them, which was indicative of slight previous haemorrhage. The midbrain and locus coeruleus showed mild loss of pigmented neurones, incontinent melanin pigment and a few Lewy bodies and Lewy neurites. Lewy bodies were also present, in small numbers, in the parahippocampal gyrus and amygdala. DNA analysis on a frozen brain sample showed no evidence of presenilin 1 mutations on fluorescent screening. APOE genotype was found to be $\in 4 / 4$.

In the light of the circumstances of this case, the coroner requested analyses of the aluminium content of affected areas of the brain. Tissue samples of frontal cortex of $<0.5 \mathrm{~g}$ wet weight were dissected, frozen and transported to Keele University on dry ice. Thawed tissues were dried at $37^{\circ} \mathrm{C}$ to constant weight and, by using screw-lid PTFE phials, digested with concentrated $\mathrm{HNO}_{3}(14 \mathrm{~mol} / \mathrm{l})$ and moderate heating on a hot plate. Digests were allowed to cool before dilution to $10 \% \mathrm{HNO}_{3}$ with ultra-pure water. The total aluminium in each digest was measured by graphite furnace atomic absorption spectrometry, using an adaptation of a programme developed in our laboratory. ${ }^{2}$ The first four tissue samples were measured blind and included the following: (a) classical Alzheimer's disease (aluminium concentration $2.46 \mu \mathrm{g} / \mathrm{g}$ dry weight); (b) neuropathology similar to that in this case, but in a person 22 years older $(4.76 \mu \mathrm{g} / \mathrm{g}$ dry weight); (c) this case $(23.00 \mu \mathrm{g} / \mathrm{g}$ dry weight); and (d) a case of depression without dementia in an elderly person ( $1.47 \mu \mathrm{g} / \mathrm{g}$ dry weight). Four further samples of frontal cortex from this case were analysed and yielded values of 3.24 and 11.01 and 4.33 and $5.71 \mu \mathrm{g} / \mathrm{g}$ dry weight for the left and right sides, respectively. One additional measurement of the similar case, 


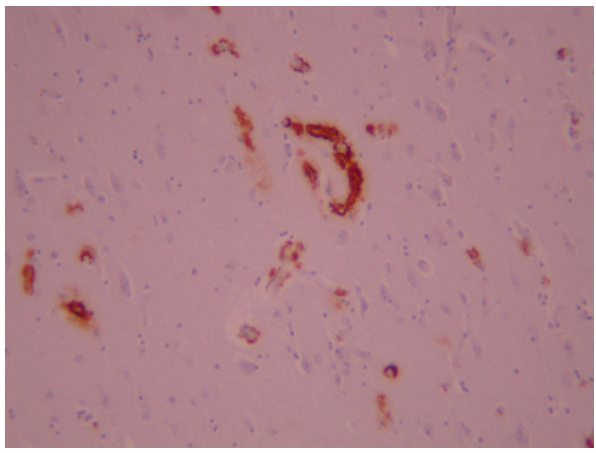

Figure 1 Low power view of cerebral cortex immunostained for $\beta$ amyloid.

(b), gave $25.16 \mu \mathrm{g} / \mathrm{g}$ dry weight. Aluminium is usually found in brain tissue in the range of $0-2 \mu \mathrm{g} / \mathrm{g}$ dry weight. ${ }^{3}$ Aluminium in the brain cortex in this case ranged from values typical of Alzheimer's disease, 3-7 $\mu \mathrm{g} / \mathrm{g}$ dry weight, ${ }^{3}$ to one value, $11.01 \mu \mathrm{g} / \mathrm{g}$ dry weight, similar to that found in aluminiuminduced encephalopathies ${ }^{4}{ }^{5}$ to a higher value, $23.00 \mu \mathrm{g} / \mathrm{g}$ dry weight, typical of dialysis-associated encephalopathies. ${ }^{46}$

$\beta$ amyloid congophilic angiopathy of variable extent is almost always found in cases of Alzheimer's disease, in which $\beta$ amyloid deposits are also found in cortical plaques with associated neurofibrillary tangles. ${ }^{7}$ Some $\beta$ amyloid precursor protein mutations rarely give rise to a familial condition with cerebral haemorrhages and dementia. ${ }^{8}$ In this condition, however, the amyloid angiopathy affects small arteries more extensively in the brain than in this case, and there are usually macroscopically visible haemorrhages, which were not seen here. No family history of cerebral neurological or psychiatric disease was evident. Thus, this case presents a very unusual pattern of severe, sporadic $\beta$ amyloid angiopathy, a condition that has been described only occasionally. ${ }^{9}$ We also noted the presence of Lewy bodies, as has been described previously in Alzheimer's disease and, in particular, in early-onset forms of the disease. ${ }^{10}$ Inheritance of APOE $\epsilon 4$ / 4 is a risk factor for the deposition of $\beta$ amyloid in the walls of cortical and leptomeningeal blood vessels, ${ }^{11}$ as well as an earlier age of onset of Alzheimer's disease, ${ }^{12}$ and this genotype may have contributed to the neuropathology observed in this case.

We are not aware of any other determinations of aluminium content in the brain in similar cases. To our knowledge, aluminium content in the brain has not hitherto been measured in any case of presenile dementia, nor has it previously been associated with the APOE genotype. The range of high aluminium content measured in the brain in this case may reflect focal deposits of aluminium, as has been observed previously in Alzheimer's disease ${ }^{13}$-for example, aluminium may be co-deposited with $\beta$ amyloid. ${ }^{14}$ Aluminium, along with iron, is implicated in the aggregation of $\beta$ amyloid in $\beta$ sheets ${ }^{15}$ and this may explain their possible co-localisation in this case. Despite both aluminium and $\beta$ amyloid being implicated in Alzheimer's disease, we can only speculate about their individual or joint roles in this case, although their association with the observed neuropathology is unlikely to be wholly adventitious. It is possible that the high content of aluminium in the brain is a consequence of a previous exposure to extremely high concentrations of aluminium in drinking water (approximately 500-3000 times the maximum allowable concentration for potable water), although this remains to be confirmed in other people from the exposed population. It is not possible to say on the basis of this evidence whether aluminium had a causative role in this case. Further follow-up to assess cognitive function in

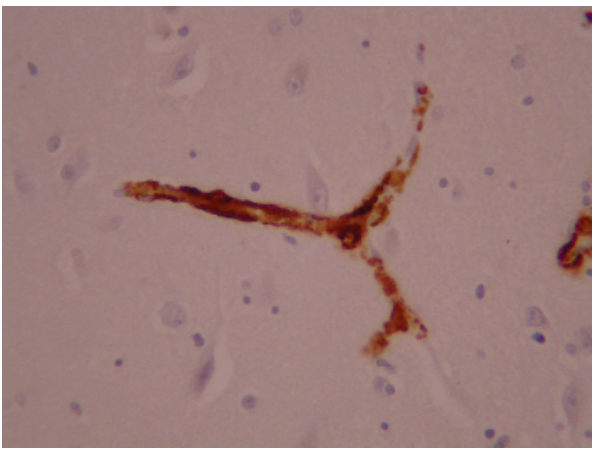

Figure 2 A higher power view of branched cortical blood vessel immunostained for $\beta$ amyloid. Note the strong staining of vessel wall and absence of staining in the neighbouring cortex.

survivors of this toxic incident, however, would seem warranted and neuropathological examination of the brains of survivors, if consent is given, should be undertaken whenever the opportunity arises.

\section{ACKNOWLEDGEMENTS}

We thank Donald Warden for performing the APOE genotyping. We also thank the coroner and the spouse of the deceased for permission to publish this material.

\section{Authors' affiliations}

C Exley, Birchall Centre for Inorganic Chemistry and Materials Science, Lennard-Jones Laboratories, Keele University, Staffordshire, UK M M Esiri, Department of Clinical Neurology, University of Oxford; Department of Neuropathology, Oxford Radcliffe NHS Trust, Oxford, UK

Funding: There was no external funding for this research.

Competing interests: None.

The examinations were carried out at the request of the Coroner's Office (MR Rose, http://www.clarkewillmott.com) and permission to publish was obtained from both the coroner and the spouse (contact information available if required). Dr Exley carried out the aluminium analyses at Keele University and Professor Esiri carried out the neuropathology at the Radcliffe Infirmary, Oxford.

Correspondence to: $\operatorname{Dr} C$ Exley, Birchall Centre for Inorganic Chemistry and Materials Science, Lennard-Jones Laboratories, Keele University, Staffordshire, UK; c.exley@chem.keele.ac.uk

Received 9 January 2006

Revised version received 8 February 2006

Accepted for publication 10 February 2006

Published Online First 20 April 2006

\section{REFERENCES}

1 Braak H, Braak E. Neuropathological staging of Alzheimer-related changes. Acta Neuropathol 1991;82:239-59.

2 Schneider C, Exley C. Silicic acid $\left(\mathrm{Si}(\mathrm{OH})_{4}\right)$ is a significant influence upon the atomic absorption signal of aluminium measured by graphite furnace atomic absorption spectrometry (GFAAS). J Inorg Biochem 2001;87:45-50.

3 Andrási E, Páli N, Molnár Z, et al. Brain aluminum, magnesium and phosphorus contents of control and Alzheimer-diseased patients. J Alzheimer's Dis 2005;7:273-84.

4 Reusche E, Pilz P, Oberascher G, et al. Subacute fatal aluminium encephalopathy after reconstructive otoneurosurgery: a case report. Hum Pathol 2001;32:1136-40.

5 Meshitsuka S, Koeda T, Hara T, et al. Abnormal aluminium metabolism in two siblings with progressive CNS calcification. Dev Med Child Neurol 2001;43:286-88.

6 Alfrey AC, LeGendre GR, Keahny WD. The dialysis encephalopathy syndrome - possible aluminum intoxication. N Engl J Med 1976;294:184-8.

7 Ellis RJ, Olichney JM, Thal $\mathrm{U}$, et al. Cerebral amyloid angiopathy in the brains of patients with Alzheimer's disease: the CERAD experience. Neurology 1996;46:1592-6.

8 Plant GT, Ghiso J, Holton JL, et al. Familial and sporadic cerebral amyloid angiopathies associated with dementia and the BRI dementias. In: Esiri MM, 
Lee M-Y, Trojanowski $J$, eds. The neuropathology of dementia. 2nd edn. Cambridge: Cambridge University Press, 2004:330-52.

9 Yamada $M$, Itoh $Y$, Suematsu $N$, et al. Vascular variant of Alzheimer's disease characterized by severe plaque-like beta protein angiopathy. Dementia Geriatr Cogn Disord 1997:8:163-8.

10 Giasson BI, Lee V M-Y, Trojanowski JQ. Parkinson's disease, dementia with Lewy bodies, multiple system atrophy and the spectrum of diseases with alpha synuclein inclusions. In: Esiri MM, Lee $M-Y$, Trojanowski JQ, eds. The neuropathology of dementia. 2nd edn. Cambridge: Cambridge University Press, 2004:353-7.

11 Yip AG, McKee AC, Green RC, et al. APOE, vascular pathology, and the AD brain. Neurology 2005;65:259-65.
12 Corder EH, Saunders AM, Strittmatter WJ, et al. Gene dose of apolipoprotein E type 4 allele and the risk of Alzheimer's disease in late onset families. Science 1993;261:921-3.

13 Solomon B, Koppel R, Jossiphov J. Immunostaining of calmodulin and aluminium in Alzheimer's disease-affected brains. Brain Res Bull 2001; 55:253-6.

14 Exley C, Price NC, Kelly SM, et al. An interaction of $\beta$-amyloid with aluminium in vitro. FEBS Lett 1993;324:293-5.

15 House E, Collingwood J, Khan A, et al. Aluminium, iron, zinc and copper influence the in vitro formation of amyloid fibrils of $A \beta_{42}$ in a manner which may have consequences for metal chelation therapy in Alzheimer's disease. $J$ Alzheimer's Dis 2004;6:291-301. 